\title{
Reflections on the Teaching of Creative Writing At the American Universities
}

\author{
Dr. Adil Jamil \\ Associate Professors of English Amman University, Jordan
}

doi: 10.19044/esj.2016.v12n22p324 URL:http://dx.doi.org/10.19044/esj.2016.v12n22p324

\section{Abstract}

Creative writing as an academic discipline has been contested since the very beginning of its existence at the American universities, and "backlash against it is always in full blood" (Burroway, 61). To critics, it seems to be softer, and less rigorous discipline, in comparison to other English studies (Elliott 100). Other critics describe it as the most undertheorized and in that respect the most anachronistic [field] in the entire constellation of English study (Haake, 83). Even some faculty members at English departments expressed mockery and sarcasm when the universities began recruiting creative writers to teach creative writing. For instance, a professor of English at Cornell University, who when told of the proposal to hire the novelist Vladimir Nabokov, said to do so would be like the Department of Zoology hiring an elephant (Dibble \& Van Loon. April 2000). In examining critics' negative stand, one may assume that it basically stems from two different misconceptions: first, critics seem unable or possibly unwilling to digest the idea that creative writing is a process-led, process-based discipline and its nature decrees different set of conventions and teaching techniques; second, it is more possibly that critics' adverse stand is based chiefly upon the performances of some incompetent instructors whose ineffective performances are taken as ground for criticism. Against all odds, creative writing has continued growing and expanding incessantly and has always received strength from its popularity and ability to recruit, and all attempts to marginalize it would be doomed to failure. Unfair and rather groundless attitudes persist regardless of the acknowledged popularity. The current study is designed to show the highlights of teaching creative writing at the American universities, and then to fairly discuss this peculiar experience and gauge its validation.

After surveying the current state of this ever-blooming discipline and the negative stand held by some critics, the study examines the commonalties, the shared conventions, and the ground rules of fiction writing workshops. A considerable number of essentials would be tackled 
such as the layout, the setting of workshop, the number of enrolled students, the requirements of completion and success, the portfolio and its contents, the role of instructor, the conduct of student author, and of student critic, and the response to peer work. The rules that govern class discussion, the instructors' theoretical assumptions, and the methods of assessing and grading student work are also examined. The careful scrutiny of the aforementioned essentials may hone the idea that creative writing is like other disciplines, if not better; it is neither softer, nor less rigorous discipline; actually it is more demanding, more rigorous, and more orderly in comparison to other English studies. Furthermore, the study would show that every activity in the workshop stems from unspoken theoretical assumptions about whether or not writers used conventions and generic expectations. Besides, this study would spotlight the effective means and methods used by competent instructors to nurture the promising, yet still unborn, talents of young writers. In brief, this study has two goals in mind: first to bring to light the shared conventions and ground rules prevalent in organized fiction writing workshops, and second to deflate the ever-blowing adverse criticism and to show the futility and groundlessness of it.

Keywords: Creative writing, fiction writing workshop, creative writers, student authors, student critic, assessment and grading

\section{Introduction}

After its inception in the first half of the $20^{\text {th }}$ Century, creative writing as an academic discipline has incessantly grown and expended at the American universities. In two decades it became a boom subject in terms of popularity and student recruitment. Burroway notes, in the 1970s creative writing became the hottest subject in the English department, the boom trade of the English bizz (Burroway, 61). During the 1990s, four fifth of all American Undergraduate programs offer courses in creative writing, almost half offer specialization in creative writing, and nearly two thirds of all Creative Writing programs are located in English departments (Berry, 243). David Fenza points out, creative writing classes have become among the most popular classes in the humanities, and he adds, to meet the growing demand, creative writing programs have at least tripled in number in the last thirty years (Vanderslice et al, 2013). Nowadays, creative writing classes are more popular than ever, in part because they offer not just a means of expression but an alternative to theory-laden literary analysis (Vanderslice et al, 2013).

Despite the rapid expansion and lasting popularity, creative writing as an academic discipline has been contested throughout its existence. Criticism of all sorts has taken aim at this relatively new discipline, and 
"backlash against it is always in full blood" (Burroway, 61). Critics unfairly label creative writing as the most under-theorized and in that respect the most anachronistic [field] in the entire constellation of English study (

Haake, 83). To critics it seems to be softer, less rigorous discipline, in comparison to other English studies (Elliott 100). Writers, recruited to teach it at universities, frequently find themselves defending and struggling against critics' attempts to marginalize, and eventually to abolish, their discipline. Unchecked mockery and sarcasm broke out when some universities began recruiting creative writers to teach. A professor of English at Cornell University, who when told of the proposal to hire the novelist Vladimir Nabokov, said to do so would be like the Department of Zoology hiring an elephant (Dibble \& Van Loon. April 2000). Such snobbish attitude of theory-oriented members has hardly changed throughout the years. Many missed no occasion whatsoever to deflate this ever-blooming discipline, and eventually called for the elimination of creative writing from the English department. To mention but one specimen, Abolish the M. F. A., states Hall with an exclamation point, and then, in Latin, he cries, "The Iowa Writers Workshop must be destroyed," (qtd. in Vanderslice et al, 2013). Against all odds, published novelists, playwrights, and poets found their way into the world of academia. Meanwhile, many writers noticeably became more popular than the rest of the faculty members at English departments, and the discipline continues growing, gaining strength from its popularity and its capacity to recruit.

A careful estimation of the state of creative writing in the university curriculum may suggest that adverse criticism is mostly groundless. More likely it is based upon the performance of a few incompetent creative writing instructors who probably do nothing at the workshops, except telling their students to be like me (Francois Camion, 5), and possibly enjoying the cock fight raised among undisciplined students while discussing peer works. As a matter of fact, incompetent and indifferent teachers can be found in any discipline, and undesired performance of a few doesn't justify the harsh criticism pointed at the entire creative writing teaching. As Dinty Moore puts it, critics of creative writing as an academic pursuit take a small, small part of the whole and attempt to paint the entire enterprise in one, inaccurate color (Vanderslice et al, 2012). Critics seem to overlook the tremendous efforts competent and highly competent instructors invest at the workshop. They pass over without given due attention to the commonalities and the delicate traditions creative instructors share. Regardless of the ever-mounting criticism, a close look at the commonalities, practices, conventions, ground rules, objectives, and theoretical assumptions seen in the majority of workshops may suggest that creative writing as a discipline is more 
demanding, rigorous and focused than most comparable disciplines at the field of English studies.

This current descriptive study, limited to fiction writing workshops, may testify for the ground rules, conventions and theoretical assumptions that have been deeply rooted and dearly embraced by competent instructors in most prestigious universities as well in some less competitive academic institutions. Before we begin our testimony, which is based mostly upon firsthand experience, one may feel inclined to mention the following two observations. First, it is true that each creative writing workshop has its own stamps depending upon the preferences and background of the instructor and the teaching of fiction and poetry varies from writer to writer; each workshop that emerges from it, has its own original stamps (Elliott, 115). Second, it is also true that most workshop instructors share the same set of ground rules, conventions, assumptions and objectives, with some minor variation. Creative writing as an academic discipline, as this study may show, is neither the most under-theorized nor the most anachronistic. The following pointers may suggest that creative writing, like other disciplines if not better, is more demanding, rigorous and focused; it has its own characteristics that distinguish the workshop from the traditional academic classroom.

\section{Layout, setting, and number of students enrolled.}

Through a close observation of a considerable number of fiction writing workshops at American universities, private and state, it has been noticed that students and instructor commune at a round table; two rows of students facing each other with the instructor taking the center stage, a small conference setting rather than the traditional setting. The number of students enrolled as recommended by the AWP is 10-15. This relatively small number offer instructors a better chance to carefully read and respond to students' works; he/she may have more review time under less pressure. At the same time, it may give students also enough time to read and share their comments on others', and to receive oral and written feedback on their own works. In practice, the real number of students enrolled in effective workshops is between 10 to 15 students at graduate workshops, whereas 15 to 20 students at undergraduate workshops. Sometimes, depending upon the popularity of the instructor, he/she may give consent to take between 2 to 3 students extra. Crowded workshops are never recommended even at the less competitive universities, and most instructors favor the recommended number, alarming that the opportunity for students to receive instructor and peer feedback on their work might be lost in randomly-filled workshops. This problem can be easily solved by the administration, not the writing instructors, by pressing restrictions on the enrolled number as well the prerequisites required to attend workshops. In the absence of such rules, some instructors use their 
own filtration process; they resort to brute labor, heavy reading and writing practices, in the first two weeks, believing that such exercises might help eliminate the number of extra students, hoping to keep only hard working students. MacDonald recommends,

Start with an assignment that requires hours of brute labor. ... you will lose a few, the ones who wanted to learn without learning to work... They [students] will learn more by writing than through anything you can say to them, ... so you give them a taste of the hard work involved, a good dose of discipline, and a frame work of procedures. (MacDonald, 83) As recommended, most competent instructors require their students to go through a workshop boot camp featuring literary skin toughening exercises, to get a taste of the hard work awaiting them at the rest of the term.

\section{Requirements of completion and success}

At fiction workshops, the ruling words at are dedication and commitment to the process not the literary merits of product. Students must be dedicated and committed to take up all the tasks assigned by instructors, reading, writing, revising, and critiquing, so as to meet the requirements of the workshops. In a graduate as well in an undergraduate fiction workshop, students are expected to write three short stories, or at least three chapters of a novella with the outline of the rest. Equally important, student works must be turned in on time, according to a strict schedule announced at the beginning of the semester. Some instructors ask for only two stories with longer length. Students are also expected to take part in all the writing and reading exercises required by the instructor. One step up from pure workshop is reading-writing workshop (Dibble \& Van Loon April 2000). Students need to read extensively to write well. As recommended by many exponents: writers must be readers. Students ought to be compulsive and omnivorous reader, to hone their writing (Macdonald, 83). They are also expected to give feedback in writing after they examine their peer works, and also to read and elaborate in class their comments and responses to others'. Students usually receive copies of their peers' written stories of a next class discussion, at least two days before the due date, and have their written responses ready on time. Absences are strictly prohibited, and students with repeated absences would lose grade as a consequence, and eventually given a friendly warning by the instructor. Tardiness and late work would be strictly penalized. Such unbending rules can be understood, when all know that the text of the daily discussion is the scheduled stories of student authors. Any late work would cause terrible disruption; thus students are required to turn in their works at the scheduled time, be it stories or critique. By and large, competent instructors never tolerate late work for any reason; and students who 
repeatedly fail to meet their obligations are often asked to drop out the course, and then the instructor may modify the announced schedule of discussion accordingly, in line with the remaining number. Due to the above, the completion of workshop requirements and success depend upon the meeting of all the designated tasks.

\section{Folder, portfolio, of students}

Most competent instructors and writing pedagogues hold that a major advantage of portfolios is that they integrate good assessment and good teaching practice tools ( Domina 1994, Murphy \& Smith 1989 , Yancey, 1992 \&1997). In line with such assumption, the folder or portfolio has become a must at any fiction writing workshop. It is a major essential that instructors ask students to supply. Every written work, be it a story, revision or written critique and responses done during the term must be carefully and neatly documented in a plain folder, or portfolio. Students are always taught that any missing piece of their writing may result in ramification of their overall grade. Documentation, as seen by many, is of great benefit for both the instructor and students. On one hand, the instructor would have documents to gauge through the progress of students and then fairly assess and evaluate their written works. On the other hand, students themselves would have a reference to turn to and see their drawbacks and highlights as marked by the instructor and classmates. Presumably, the feedback students receive would help a great deal in revising the first draft, and also in writing their next story. Student authors more possibly take into consideration the instructor's feedback and peer critique to improve writing and avoid the cited defects of their first trial. As a general practice, after students turn in their assignments, instructors would have their work examined, responded to, signed and dated, and then given back to students to keep in their folders, however without being graded. By the end of the semester, the folder is expected to comprise the first version of stories, the revised version, together with copies of written critiques of others' stories, in addition to any other written or reading exercises assigned by the instructor. At least a week before the end of the semester, students' portfolios would be collected by the instructors and a final grade would be given after careful inspection of all the contents and the progress a student achieved throughout the semester.

\section{Role of the instructor}

In his comment upon the duties of the scholar, Ralph Waldo Emerson says, The office of the scholar is to cheer, to raise, and to guide men by showing them facts amid appearances (Emerson, The American Scholar, 1837), a statement ever held dearly by scholars and artists, and its echo is still felt in the conduct of writers involved in teaching creative writing. The instructor 
of a fiction workshop takes the role of a conductor, a director, a stage manager and a teacher at the same time. Their chief office is to foster optimism rather than depression while coaching, training, encouraging, and initiating students into the art of creative writing. In Domina's words, I try to foster a workshop atmosphere where it is safe to take risks, be encouraging to tread unfamiliar or foreboding a territory in form and content. One of my personal goals in teaching is to encourage students to discover their passion and embrace it (Domina 29). Teachers who sit and listen to the cock fight and read roughly students' work and proved mere feedback will never manage to live up to their commitment as a creative writing teachers. Mere reactive feedback, a general and an unsubstantiated response, such as great, poor, good, interesting, would contribute nothing to students' works (Zeigler 211-12). Committed teachers are always willing to read and give prescriptive feedback on a regular basis to help mend the defects in student works. Prompt responses and prescriptive feedback would encourage students to take their writing seriously and then work enthusiastically to produce better pieces led by the constructive comments of their instructor and peer critique. John Gardner recommends that teachers must encourage risk-taking and independence. Gardner conceptualizes, in a bad workshop, the teacher takes the place of students' critical imagination (Gardner 1983, 86), in other words dictating more than cheering or inspiring. Led by Gardner's thought, Moxley recommends:

We [instructors] need to embrace the concept that providing students with lots of opportunities to write about subjects they care about will promote writing independence more than endless hours of talk about writing or grammar. (Moxley, 34)

Beside constructive feedback, competent instructors familiarize students with the popular genres and then leave them decide for themselves. To help students write better and speak critically, instructors should, introduce students to the expectations of popular genres such as horror, suspense, mystery, science fiction, fantasy, and children literature. Along with exploring ways to generate materials, we need to develop methods to teach students to be critical readers and editors of their own writing. (Moxley, 36)

Beside writing and revising, instructors often engage students into reading practices led by the idea that students, through reading, may explore ways of generating materials, and then internalize concepts for themselves to apply in their writing. Most instructors hold that students need to read and write extensively to write well. 
In their comments, instructors should be more careful in using specific terms and vocabulary that students use in both their writing and comments upon others'. Most instructors believe that students have the potentials to tell interesting stories and only need an inspiring instructor to pull out carefully and neatly the new born pieces. After birth, instructors can use their expertise to mend the defects. No matter how poor the student's work is, instructors are inclined to overlook the setbacks and look for some highlights and build upon to help improve poorly written stories. Discouragement and ticking off have no place in especially undergraduate workshops. What matters is the commitment of students and their willingness to abide by the rules of the workshop. Some students are naturally creative writers, others are naturally good critics who can at ease pinpoint highlights and drawbacks in the works of classmates. Thus, instructors are expected to recognize the cited potentials in their young students and build upon. The inclass critique must be carefully tuned by the instructor. Sometimes, comments are made without knowing their long term effects for both beneficial and detrimental (Ziegler, 209). Mimi Schwartz agrees with Ziegler; she notes,

the astonishing power of response was either to encourage or undermine creative risk-taking... Instructor's response to others, must be constructive, positive, and careful not to damage the goods, so to speak, in delivery (Schwartz, 204).

Writing instructors may gear the in-class discussion first to the points of strength and highlights seen in stories, at the same time try to play down the drawbacks if possible. Student writers should feel appreciated and motivated to better put their stories or critique. To better tune the discussion, Haake, one of the brilliant exponents of the genre explains her technique,

I would add a critical framework and vocabulary; I would teach them [students] how to talk about texts. ... I introduce concepts of story and discourse, sequential ordering, narrative strategy, narrative stance, narrative stance, temporality, focalization, structure itself. (Haake, 77-78)

Instructors' attitude, as aforementioned, is to foster optimism rather than depression in students. The instructor, at least after the first set of stories and sessions of discussion, would become fully aware of students potentials, strength and weaknesses, and then build upon his/her discoveries. The teacher, then, participate in a process of discovery-praising, provoking, guiding, and referring (Elliot, 116). In accord with discoveries, instructors may adjust their comments on both the written stories as well as on the pieces of critique students turn in. Instructors also need to carefully consider how large and frequent the dosages of criticism should be. It is not always necessary to mark red all the mistakes seen in a story or written critique. Bleeding versions might be more offending than inspiring. Rather, one may 
mark what can be fixed by students and overlook the other defects for the next trial.

Instructors are expected to teach students how to talk about texts, what to press and what to overlook. To produce well- structured comments, some instructors often supply guidelines for students to go by when evaluating their fellow students' work. (See Appendix I). Furthermore, to avoid the expected in-class cock fight, instructors may supply another version of guidelines optionally filled out by willing students and delivered directly to the instructor but not to the student author. (See Appendix II). This second version may give a student critic a private outlet to explain whether the discussed story is original, or it might be entirely plagiarized, and to say what he/she pleases without reservation, for nobody is going to see the private version except the instructor. The awareness of students of the second set of guidelines may help eliminate any attempt of plagiarism and then subsequently push students to produce their own original stories. Equally important, to lessen the pressure on student authors, instructors should often remind students that writing is a gradual process improved only through errors and trials, and the final grade depends chiefly upon how good the final story would be, for this final piece marks the progress and the skills a student acquires during the term.

\section{Student author and student critic}

There are a set of rules that most creative instructors strictly observe during the group discussion of stories produced by student authors. These rules are clearly explained to students enrolled in the workshop and all must abide by. The instructor is accountable for enforcing the ground rules and to keep things in check. Before the session, students should be made aware that the purpose behind students' critique is mainly to help the author improve the written piece. In the same connection, student critics are always advised to avoid reactive or random critique that may offend the author and mar the whole piece. Any defect marked by a student critic must be accompanied by suggestions to help treat the cited defect. The student critic must be taught to elaborate first on the highlights of language, the best defined and portrayed character, the best developed scene, the arrangement of events, the symbols, and the use of supernatural machinery if there is any. Afterwards, the critic may refer to the places that should be modified and improved; critique must always be accompanied with suggestions. Furthermore, student critics must be honest, kind, specific, and focused, and their critique must be directed to the work not the author.

A student author should go by the common advice, take in and don't defend. He/she should learn to endure bravely without complaining or protesting even if the critique is most degrading, ridiculous and subjective, unless he/she is asked by student critics to respond, pending the instructor 
allows the elaboration.. However, a student author does not always sit quietly while his work is read in front of him,... as peers shred his work or occasionally praise it, as one of the ardent critics of workshop teaching alleges (Shivani, 2012). In practice, a student author is often given many chances to elaborate, for instance on the purpose or theme, characterization, scenic background, or even unclear expressions he/she uses in the discussed story. To lessen the pressure on the author, the instructor takes sometimes the role of attorney playing down the mistakes cited by critics, but not harshly shunning objective criticism.

To run things smoothly and peacefully, instructors encourage students to respect each other and their work. No hostile attack is allowed. Any streak of harsh or degrading criticism must be banned. A harsh critic must be always notified in private to abate his/her malice while discussing the work of fellow students. Lynn Domina insists that,

The respect must be demonstrated across horizontal as well as vertical relationships. A teacher's respect will be insufficient if student's classmates express ridicule, but a teacher can certainly model and guide classes toward tolerance, and this is one of the few situations in which I believe a power relationship can be justifiably exploited. (Domina, 30)

However, vigorous student critics should be allowed to lay their ideas freely and frankly in the private version of evaluation they deliver to the instructor. This copy is not to be seen by the student author, as a result no cock fight will take place in the classroom. Out of experience, very few excited students are willing to fill out this version. It is worth mentioning here that some private evaluations prove helpful in detecting plagiarism some students resort to, such as picking the whole story from a cyber-site, or any other source. Plagiarism is expected especially at workshops fraught with poorly skilled students, and instructors are certainly aware of.

\section{Points to emphasize and point to overlook}

When discussing a student story, the points to be tackled are certainly not the basic writing mechanics, such as spelling or grammatical mistakes. Writing mechanics should be overlooked in the oral discussion, but there is no harm to refer to conspicuous errors in the written copy which is usually delivered after discussion to both the instructor and the student author. Artistic concerns are the points to be tackled, such as the plot, arrangement of events, character portrayal, the scene management, and probability of events, physical and spiritual or mental description. Beside these, the type of language used is another concern that the instructor would lead students to discuss. Last but not least, students may be asked to cite the awkward expressions if there are any. As a tradition in well-organized workshops, the comments should be written and delivered in two copies, one goes to the 
instructor and one goes to the author. Students should be trained to press the points of strength and pay less attention to the points of weakness, as most creative writing instructors believe that encouragement would stimulate selfconfidence and help students produce better stories. Discouragement, on the other hand, would offend novice writers and may suspend the faculty of creating and more possibly students, especially poorly-skilled ones, lose interest in the whole process and see themself unfit to move on. Domina notes,

Despite having met the prerequisites for the course, some students lack sufficient skills to succeed-which obviously may have ramifications on their ultimate grade, but also can have ramifications on classroom dynamics. Students' reaction to work fraught with grammatical errors may express emphatic embarrassment, patronizing encouragement, and open disdain. (Domina, 33)

Still, a competent instructor is able to contain unfavorable reaction; he/she may play down conspicuous errors and gear the discussion to more important issues rather than dwelling upon misspelling and grammatical mistakes. Pressing basic writing mechanics would certainly turn the workshop into a basic writing class at a writing clinic.

\section{Theoretical assumptions}

During the 1980s and 1990s, the pioneers of creative writing have implied, and occasionally stated, in their works and practices a set of theoretical assumptions they often draw upon. These assumptions, that still govern the conduct and practices of the majority of instructors at the workshop, can be summarized as follows. First, they all hold that there are aspects of the creative process difficult to quantify, codify, and convey; and arts can be taught and learned up to a point; but for certain matters of technique, students do not learn the arts, they might catch on. Accordingly, instructors focus upon the teaching of the common techniques that may help students catch on and then leave them on their own to compose their stories. Second, a writer can be nurtured but not taught. Writers believe that there no ready-made rules available for students to contain and then to be tested against. Writing and reading practices may help them internalize and conceptualize and then apply in their writings. Third, since great art is based upon nonconformity; thus instructors ought to encourage risk-taking and independence. They often encourage their students to create their own original stories rather than blindly imitate others. Fourth, literary theories hamper rather than foster creativity, especially in undergraduate workshops. Literary theory has been accused, by many creative writers, of being incomprehensible and jargon-filled (Eagleton 2003, 76; Isenberg 2007). Furthermore, some writers believe that theory turns artists into puppets 
whose strings are jerked by some higher power (Sanders, 11). In simple words, theory suspends or interrupts the natural growing of students' potentials. For this reason, many instructors guard their students against the infection of theory. They avoid messing with theoretical terms such as formalism, structuralism, semiotics, post-structuralism, and deconstruction. These terms, they think, may frighten novice writers and scare them off. Instead, instructors resort to more familiar and non-threatening stock of critical terms, like round, flat, type, and individual characters, point of view, narrative persona, flashback, overshadowing, foreshadowing, showing versus telling, unity of effect, mental and physical description, scenic background, correspondence of nature and events, investment of dreams or supernatural elements. Fifth, creative writers assume that creative writing is a practiceled and process -based discipline. Thus the process is to receive more attention and importance at the expense of the product. The engagement of students in the process, writing, revising, reading, evaluating peer works, commitment, and respect of deadlines may initiate, but not necessarily lead, students into the painstaking road of publishable arts. Creative writers at workshops cannot teach the mysterious side of art, except, as Dinty Moore puts it,

to offer the occasional guiding thought or idea, the craft lesson, a few instructive models, and the occasional critical nudge, while all the time encouraging the student to practice writing, to practice revising, and practice, practice as a means to improvement. (Vanderslice et al, 2012).

\section{Assessing and grading students writing}

As aforementioned, most instructors and writing pedagogues agree that creative writing is hard to quantify and codify. It isn't informational and can't be made so; it is not a containable subject and demands the scrutiny of subject-the great books (Tanner, 10). In addition, there is no identified number of templates for a good story, a well-thumbed story, available for instructors to use in measuring students' creative writing. At the same time, no should not defend one story against the next, for each fiction establishes its own aesthetics and moral universe and must stand on its own merits (Elliott, 114). Due to the above, the basis of assessment and grading is different from the one currently used in measuring student performance in literary studies. In most creative writing workshops, the final grades are based upon the whole body of work achieved by students. Writing and reading exercises, drafts, and quality of revision are taken into full consideration when signing the final grade. What matters to instructors is the process not the product. The time invested, the efforts endured, and the 
industrious attempts of students to improve their writing are more important to competent instructors than the artistic merit of the work they turn in. No instructor in his/her right mind expects students to produce masterpieces at workshops. The industrious attempt to follow the given feedback is more important than product itself. As a practice, in most workshops, the first two pieces, no matter how good or poor, remain ungraded. Instructors provide only prescriptive feedback, detailed comments to help students better revise their stories, and afterwards, the quality of revision is considered as one of chief factors in determining the final grade the writer receives. The third piece often carries more weight, than the earlier ones. More likely the final piece speaks for the growth students accomplish throughout the term. Grading all the pieces separately then counting the grades students score on the different pieces is neither recommended nor used by competent creative writing instructors. Banks sees the work on a continuum, not as an isolated piece of writing. Compared to earlier pieces, the writer was taking imaginative risk and Banks wanted to praise the efforts more than he wanted to dwell on the problems (Schwartz, 205). Thus, the final grade is to indicate what students have accomplished at the end of the workshop. Besides the grades the written stories and exercises receive, other factors are also considered and may adjust the final grade such as attendance, due dates, conduct, classroom participation, growth over the semester, and the meeting of deadlines, at the same time the reaction of students to the written stories, for students at the workshop more or less represent a sample audience. As Boice puts it, each piece of writing needs not be graded separately. Portfolio grading and students conferences ameliorate the evaluation process, and in addition to their other purposes, journal writing and written responses can also serve as supplemental bases for course grades (Boice, 473).

In conclusion, the above description of the shared conventions may abate the malice of some critics and give validation to creative writing as an academic discipline. The practices of competent instructors suggest homogeneity, rigor, and the existence of ruling conventions and theoretical assumptions that most strictly held and observed. The layout, the setting of fiction writing workshop and the number of students enrolled are almost identical. The requirements to achieve completion and success in a workshop are nearly the same with some minor variation. The folder, or portfolio of students and what it comprises is another point of agreement in the majority of workshops. The role of the instructor is also well-defined and carefully carried out by competent instructors. There are also shared rules that govern the discussion in the workshop; each member of the triangle, the instructor, the student author, the student critic is aware of the rules and obliged to abide by. Furthermore, what to focus on and what to overlook while discussing in class peer works are also understood and practiced by 
instructors and students. The theoretical assumptions, which govern the conduct of instructors, are displayed and implied in the practices of competent instructors. Due to the above, creative writing is not the most the most under-theorized nor the most anachronistic as many opponents describe. It is more demanding, rigorous, and focused than the rest of English studies. Finally, one may suggest that this peculiar and everflourishing discipline should be earnestly reconsidered by curriculum designers so as to be included in the curriculum of universities worldwide.

\section{References:}

Amabile, Teresa. The Social Psychology of Creativity: A Componential Conceptualization. Journal of Personality and Social Psychology, 45 (1983): 357-76.

Belanoff and Dickson. Eds. Portfolios: Process and Product. Portsmouth, NH: Boynton/Cook- Heinemann. 1991.

Berry, R.M. Literary History, Theory and Practice. The Centennial Review, 36.2, (Spring 1992): 243-264.

Bishop, Wendy. Crossing the Lines: On Creative Composition and Composing Creative Writing. in Bishop's and Ostrom's Colors of a Different Horse. Urbane, Illinois, (1994): 181-197

Boice, Robert. The Neglected Third Factor in Writing: Productivity. CCC 36 (December 1985): 472-80.

Brook Mirtz, Evans. Small Groups in Writing Workshops. Urban, IL: NCTE. 1994.

Burroway, Janet. The American Experience. in Moira Monteith and Robert Miles, eds.

Teaching Creative Writing, Open Univ. Press. Buckingham, (1992): 59-65.

Camion, François. The Workshop and its Discontents. in Colors of a

Different Horse. (1994): 3-7.

Chappell, Fred. First Night Once More. South Atlantic Quarterly 84:1

(Winter 1985): 27-36.

Dibble, Brian, and Julienne Von Loon. Writing Theory and/or Literary

Theory. Vol. 4 No 1, (April 2000).

http://www.textjournal.com.au/speciss/issue3/exegesis.htm

Domina, Lynn. The Body of My Work Is Not Just a Metaphor. in Colors of a Different Horse. (1994): 27-34.

Eagleton, T. After Theory: Basic Books. Cambridge, MA. 2003.

Elliott, Gayle. Pedagogy in Penumbra: Teaching, Writing, and Feminism in the Fiction

Workshop. in Colors of a Different Horse. (1994): 100-126

Elbow, Peter. Being a Writer Vs. Being an academic: A Conflict in Goals.

CCC 46.1 (1995): 72-83. 
Gardner, John. On Becoming A Novelist. New York: Harper and Row Publishers, 1983.

Haake, Katharine. Teaching Creative Writing If the Shoe Fits. in Colors of a Different Horse. (1994): 77-99

Huber, Bettina. Appendix: A Report on the 1986 Survey of English

Doctoral Programs in Writing and Literature. The Future of

Doctoral Studies in English. Ed. Andrea Lunsford, Helene Mo glen and James F. Stevin. New York: MLA. (1989): 121-76.

Isenberg, N.. Theory out of bounds. Ruritan. 21:1. (2007): 82-103.

Kroll, J. \& G. Harper. Eds. Research Methods in Creative Writing. Palgrave MacMillan: London. (2012): 121-156.

MacDonald, John. Guidelines and Exercises for Teaching Creative Writing.in Joseph M. Moxley ed. Creative Writing in America. Urbana, Illinois. (1989): 83-88. Malone, Eileen. Writers Groups, Conferences, and Workshops. New York: John Wiley \& Sons. 1996.

Moxley, Joseph. Tearing Down the Walls: Engaging the Imagination. in Creative Writing in America. (1989): 25-46.

Sanders, Scott Russell. The Writer in the University. AWP Chronicle, 25.1 (September 1992): 1, 9-13.

Schwartz, Mimi. Wearing the Shoe on the other Foot. CCC. Vol. 40, No. 2 (May, 1989): 203-210.

Shivani, Anis. Can Creative Writing be Taught? Therapy for the Masses. (Jan 12, 2012). http://www.huffingtonpost.com/anis-shivani/creativewriting- teaching_b_1178279.html

Tanner, Ron. How to Be an Artist in the Anthill Academe. AWP Chronicle (April 1991): 1-11.

Vanderslice, Stephanie, et al. Creative Writing Can Be Taught: CR

Professors Answer Important Questions. (2012)

http://americanbookreview.org/pdf/infocus_30.4.pdf

Vanderslice, Stephanie, et al. Essay defending the way creative writing is taught. (July 5, 2013. https://www.insidehighered.com/views/2013/07/05/ Yancey. Kathleen Blake, ed. Portfolios in the Writing Classroom: An Introduction. Urbana, IL: National Council of Teachers of English, 1992. Yancey \& Weiser. Eds. Situating Portfolios: Four Perspectives. Login, UT: Utah. NP. 1997.

Ziegler, Alan. "Midwifing the Craft-- Teaching Revision and Editing.” in Moxley's Creative Writing in America. (1989): 209-225. 
Appendix I

1. The story

Points to Consider (seen Version)

Date: written by

is original, modified story which the writer took from

2. These are the best expressions which I found in the story:

a.

b.

3. The best defined and developed character is

4. The undeveloped and less defined one is Suggestions:

a.

b.

5. The well developed scene is

6. The least developed scene is

Suggestions:

a.

b.

7. The main purpose of the story is to.

8. The highlights of the story are:
a.
b.
c.

9. The drawbacks of the story are
a.
b.
C.

10. The following are awkward expressions and need to be revised:
a.
b.
c. 
Appendix II

Points to Consider (Unseen Version)

Name.

Title of Story:

by

a. Originality....

b. The Scene Management.

c. The Portrayal of Characters.

d. The arrangement of events (Plot)

e. The Language used

f. Your Final assessment of the story. 